\title{
Smoking habits and risk of fatal stroke: 18 years follow up of the Oslo study
}

\author{
L Lund Håheim, I Holme, I Hjermann, P Leren
}

\begin{abstract}
Study objective - To examine the risk of fatal stroke in relation to smoking habits in men screened for the Oslo study.

Design - The Oslo study is a prospective, cohort study of the epidemiology and preventive aspects of cardiovascular diseases in middle aged men. Screening started in May 1972 and results after 18 years of follow up are reported.

Participants - There were 16209 men aged 40-49 years, of whom 16173 had no stroke history. Eighty five men died from stroke, of whom 48 were daily cigarettes smokers, 7 were pipe and cigar smokers, 15 smoked cigarettes and pipe or cigars daily, 11 were previous cigarette smokers, and 4 had never smoked cigarettes.
\end{abstract}

Main results - Results of proportional hazards regression analysis adjusted for age, diastolic blood pressure, and glucose concentration showed the following rate ratios (RR) (95\% confidence interval) of smoking groups compared with those who had never smoked or had previously smoked: combined cigarette and cigar or pipe smokers, $R R=6.1 \quad(3.0,12.5)$; cigarettes only, $R R=4.1(2.3,7.4)$; and pipe and/or cigars only $R R=2.2(0.9,5.5)$. The overall, age adjusted risk of smoking cigarettes daily was 3.5 and was found to increase with increasing cigarette consumption. Regardless of their smoking group, stroke cases had increased diastolic (DBP) and systolic blood pressure (SBP) when compared with men who had not had a stroke. The absolute differences in DBP and SBP between stroke cases and others for never and previous cigarette smokers versus daily smokers were twice as large: DBP, $12.1 \mathrm{mmHg}$ versus $6.5 \mathrm{mmHg}$ respectively and SBP, $16.0 \mathrm{mmHg}$ versus $7.1 \mathrm{mmHg}$ respectively. A high BMI increased the risk of fatal stroke of never and previous cigarette smokers. Men being treated for hypertension at the time of screening had three times the crude risk of fatal stroke of men who were not taking hypertensive treatment.

Conclusions - Daily cigarette smoking increased the risk of fatal stroke three and a half times. Combined cigarette and pipe or cigar smoking had a higher risk than smoking cigarettes only. An increased risk was found in relation to increased daily cigarette consumption.

( $f$ Epidemiol Community Health 1996;50:621-624)
Doll and Peto, ${ }^{1}$ in the 20 years' follow up of the male British doctors study, showed that smoking contributed directly or partly causes of death. Cerebral thrombosis was considered partly attributable to smoking. In their 40 years' follow up, ${ }^{2}$ they concluded that the results at 20 years were an underestimate of the hazards of tobacco use. Results after 20 years' follow up showed that pipe and/or cigar smokers showed a non-significant increase in mortality from cerebral thrombosis. Cigarette smokers were at higher risk than combined cigarette and pipe/cigar smokers. Mortality from stroke in men who had never smoked regularly decreased by $31 \%$, whereas stroke mortality in current cigarette smokers decreased by only $3 \%$ between the first 20 year period and the next. Hickey et $a \mathcal{l}^{\beta}$ examined cigar and pipe smoking in relation to four year survival in coronary patients. They found that cigarette and cigar smokers were at significantly increased risk and that the risk in pipe smokers was also increased but not significantly so. The risk of stroke associated with cigarette smoking has been confirmed in other studies. ${ }^{4-9}$ Shinton and Beevers ${ }^{10}$ concluded in their meta-analysis of cigarette smoking and stroke that, "The meta-analysis provides strong evidence of an excess risk of stroke among cigarette smokers. Stroke should therefore be added to the list of diseases related to smoking." Higa and $\mathrm{Da}-$ vanipour, ${ }^{11}$ in their literature review of smoking and stroke, found a dose-response relationship for cigarette smoking in two of six cohorts (only one study in women).

This study aimed to analyse the association between smoking and the occurrence of stroke over a period of 18 years, the risk in relation to different smoking habits, and the risk associated with increasing daily cigarette consumption.

\section{Methods}

The Oslo study began in May 1972. All men aged 40-49 years and a 7\% sample of men aged 20-39 years living in Oslo were screened. The following report concerns the men aged 40-49 years who attended the screening and had no history of stroke. Included in this group were 16173 men who have been followed up for 18 years with regard to stroke mortality. The last day of observation was 31 December 1992.

Briefly, the screening procedures were as follows. ${ }^{12}$ The men answered a questionnaire on previous symptoms or history of cardiovascular diseases, diabetes, drug treatment for hypertension, use of nitroglycerine, physical activity at work and leisure, and symptoms of 
Table 1 The stroke mortality rate, crude and adjusted, after 18 years' follow up in relation to smoking habit at screening for Oslo men aged 40-49 years with no stroke history at baseline

\begin{tabular}{lllllll}
\hline Smoking group & $\begin{array}{l}\text { At risk } \\
(N)^{*}\end{array}$ & Person-years & $\begin{array}{l}\text { Cases } \\
(n)^{*}\end{array}$ & $\begin{array}{l}\text { Crude } \\
\text { rate* }\end{array}$ & $\begin{array}{l}\text { Adjusted } R R \\
(95 \% \text { CI) }\end{array}$ & $\begin{array}{l}\text { Adjusted RR } \\
(95 \% \text { CI) }\end{array}$ \\
\hline Never smoked cigarettes & 3073 & 53593 & 4 & 0.075 & 1.0 & 1.0 \\
Previously smoked cigarettes & 3991 & 69000 & 11 & 0.159 & $2.1(0.7,6.5)$ & 1.0 \\
Pipe/cigar only & 1623 & 27226 & 7 & 0.257 & $3.6(1.05,12.3)$ & $2.2(0.9,5.5)$ \\
Cigarettes only & 6150 & 102010 & 48 & 0.471 & $6.7(2.4,18.5)$ & $4.1(2.3,7.4)$ \\
Cigarettes + pipes/cigar combined & 1336 & 22111 & 15 & 0.678 & $9.8(3.3,29.6)$ & $6.1(3.0,12.5)$ \\
\hline
\end{tabular}

* Crude rate: rate per 1000 person-years; N - number of persons at risk; $\mathrm{n}$ - number of cases; RR - adjusted rate ratio as determined by the Cox proportional hazards regression analysis, adjusted for age, diastolic blood pressure, and glucose; CI confidence limits.

stress. At screening they had a non-fasting blood sample taken to measure their total serum cholesterol, triglycerides, and glucose levels. Height, weight, and systolic blood pressure (SBP) and diastolic blood pressure (DBP) were measured. Relative weight/body mass

Table 2 Mean (SD) of risk factors for stroke mortality for stroke cases and others in relation to smoking habits in men aged 40-49 years

\begin{tabular}{|c|c|c|c|c|}
\hline \multirow[t]{2}{*}{ Risk factor } & \multicolumn{2}{|c|}{ Never and previous smokers } & \multicolumn{2}{|l|}{ Daily smokers } \\
\hline & $\begin{array}{l}\text { Cases } \\
(n=15)\end{array}$ & $\begin{array}{l}\text { Others } \\
(n=7049)\end{array}$ & $\begin{array}{l}\text { Cases } \\
(n=70)\end{array}$ & $\begin{array}{l}\text { Others } \\
(n=9039)\end{array}$ \\
\hline $\begin{array}{l}\text { Diastolic blood pressure }(\mathrm{mmHg}) \\
\text { Systolic blood pressure }(\mathrm{mmHg}) \\
\text { Total cholesterol }(\mathrm{mmol} / \mathrm{l}) \\
\text { Triglycerides }(\mathrm{mmol} / \mathrm{l}) \\
\text { Glucose }(\mathrm{mmol} / \mathrm{l}) \\
\text { BMI }\left(\mathrm{kg} / \mathrm{m}^{2}\right) \\
\text { Height }(\mathrm{cm}) \\
\text { Physical activity at leisure }(1-4) \\
\text { Physical activity at work }(1-4)\end{array}$ & $\begin{array}{l}99.5(11.7) \\
151.7(18.7) \\
6.5(1.0) \\
2.5(1.4) \\
7.0(4.3) \\
27.4(3.8) \\
178.1(5.8) \\
2.1(0.6) \\
1.9(0.9)\end{array}$ & $\begin{array}{l}87.4^{*}(10.9) \\
135.7^{*}(15.9) \\
6.3(1.1) \\
2.1(1.4) \\
5.8^{*}(1.2) \\
24.9^{*}(2.9) \\
177.8(6.5) \\
2.1(0.6) \\
1.6(0.8)\end{array}$ & $\begin{array}{l}92.9(12.3) \\
142.8(18.3) \\
6.5(1.0) \\
2.4(1.1) \\
5.9(1.0) \\
24.5(3.4) \\
176.9(6.9) \\
1.8(0.6) \\
1.9(0.8)\end{array}$ & $\begin{array}{l}86.4^{*}(11.2) \\
135.7^{*}(16.8) \\
6.5(1.2) \\
2.4(1.4) \\
5.8(1.3) \\
24.6(3.0) \\
177.1(6.5) \\
1.9(0.6) \\
1.9(0.9)\end{array}$ \\
\hline
\end{tabular}

$* t$ test; $\mathrm{p}$ value $\leq 0.001$

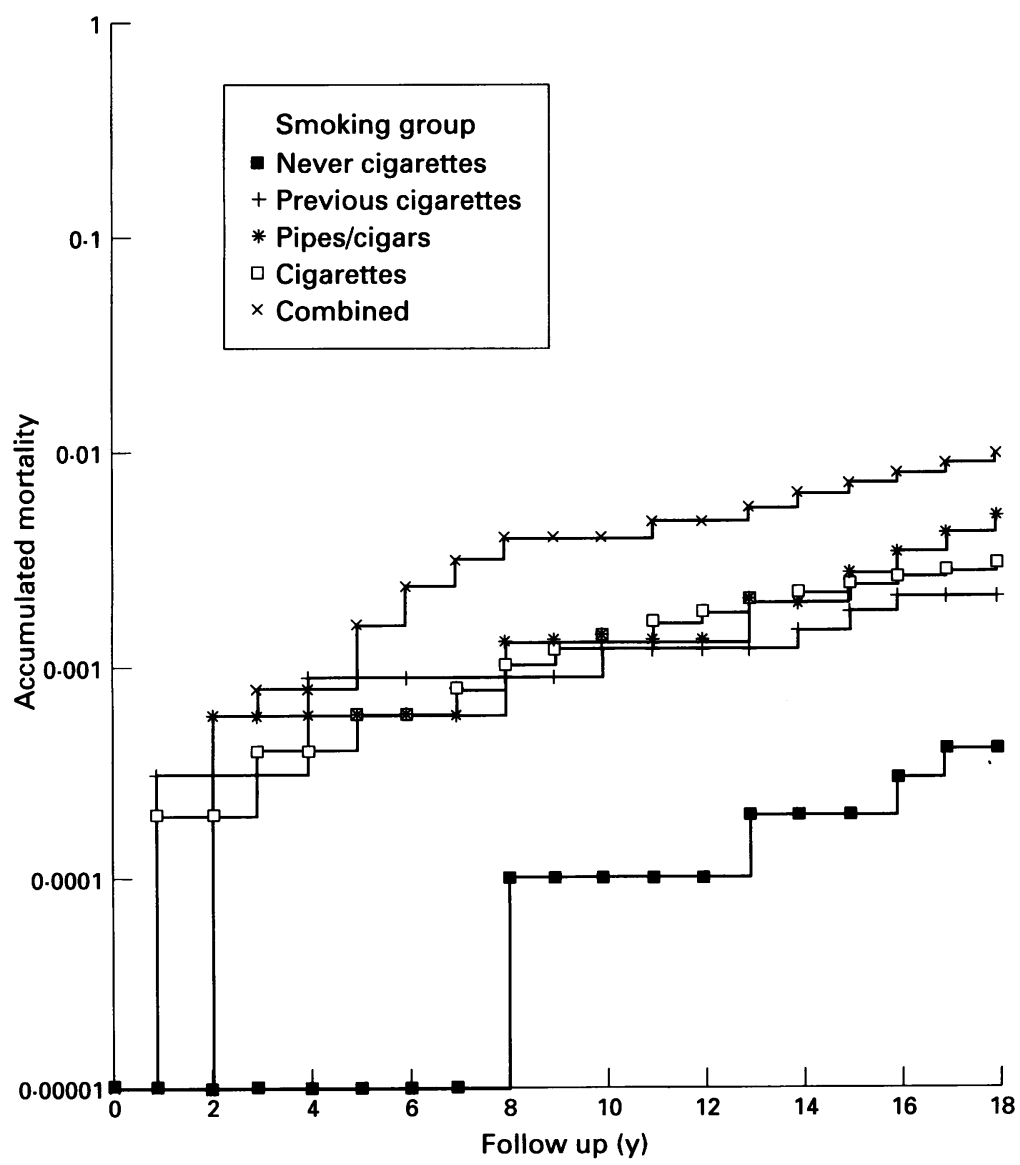

Figure 1 The accumulated stroke mortality rate over 18 years (Aalen-Nelson) in relation to smoking groups in Oslo men. index (BMI) was calculated as weight per height squared. Physical activity at work and leisure was recorded as sedentary, moderate, intermediate, or vigorous (1-4).

Smoking habits were recorded with regard to how often and what the men smoked, consumption, inhalation, duration, and, for exsmokers, the time since quitting smoking. The number of cigarettes were recorded as 1-4, 5-9, 10-14, 15-19, 20-24, 25+. The figures were aggregated into groups of $1-9,10-19$, and $20+$ for graphic presentation. The quantity of tobacco consumed by pipe and cigar smoking was not considered in these analyses. "Never" and "previous" cigarette smokers were grouped together in most analyses. Questions that would enable a "never smoker" group to be defined were not asked. Data were not sufficient for analysis related to time since quitting smoking. The following analyses are based on screening data only.

The stroke diagnosis was based on data from Central Bureau of Statistics using the codes 430 to 438 of the 8 th and 9th revision of the International Classification of Diseases. Only the main diagnosis was used.

Rates of cases per 1000 person years were used for group comparisons. Risk factors were described in terms of mean(SD). $T$ tests were used to test mean differences between stroke cases and others for daily and non-daily smokers. The proportional hazards regression analysis (Cox) was used to analyse the risk factors' predictivity for stroke mortality presented by the rate ratio (RR) and $95 \%$ confidence interval (CI). The accumulated rate of stroke mortality represented by the AalenNelson estimator was used to present mortality graphically over the 18 years for different groups. Adjustment was made for observations grouped in time periods of one year.

\section{Results}

All smokers, whether they smoked cigarettes, pipes, or cigars, carried an increased risk of fatal stroke (table 1) compared with those who had never smoked cigarettes. Previous cigarette smokers had a doubled risk (NS), those who smoked a pipe or cigars only had 3.6 times the risk, those who smoked cigarettes only had 6.7 times the risk, and men who smoked cigarettes and a pipe or cigars daily had a risk that was nearly 10 times greater than men who had never smoked cigarettes. When comparing the smoking groups to never and previous cigarette smokers combined, these adjusted risk es- 
Table 3 Proportional hazards regression analysis (Cox) of the risk of stroke mortality in relation to daily cigarette smoking versus non-daily cigarette smoking in men aged $40-49$ years $(n=16173)$. Results are presented in terms of regression coefficient, $S E$, rate ratio $(R R)$, and $95 \%$ confidence interval (CI) by one unit change of coded variable

\begin{tabular}{|c|c|c|c|}
\hline Risk factor & Coefficient & $S E$ & $R R(95 \% C I)$ \\
\hline $\begin{array}{l}\text { Model } 1: \dagger \\
\text { smoking }(1=\text { yes, } 0=\text { no) }\end{array}$ & $1.255^{*}$ & 0.248 & $3.5(2.2,5.7)$ \\
\hline $\begin{array}{l}\text { Model 2: } \dagger \\
\text { consumption }(0-6) \S\end{array}$ & $0.264^{*}$ & 0.052 & $1.30(1.18,1.44)$ \\
\hline $\begin{array}{l}\text { Model 3: } \\
\text { consumption }(0-6)\end{array}$ & $0.257^{*}$ & 0.052 & $1.29(1.17,1.43)$ \\
\hline
\end{tabular}

${ }^{*} p$ value $\leq 0.05$. + Model $1-2$; adjusted for age. $¥$ Model 3 ; adjusted for age, DPB, glucose. $\$$ Coding of cigarette consumption: $0=$ non-daily cigarette smokers, $1=1-4,2=5-9,3=$ $0-14,4=15-19,5=20-24,6=25+$.

timates were reduced to 2.2 (pipe/cigar only), 4.1 (cigarette only), and 6.1 (cigarette and pipe or cigarette). The fact that DBP and glucose were negatively correlated to smoking for stroke cases of daily smokers and non-daily smokers (table 2) explains the somewhat stronger association of adjusted rates versus crude rates of stroke mortality. Time trend analysis by a Aalen-Nelson plot (fig 1) shows the difference in the accumulated rate of stroke mortality in relation to smoking habits. The rate ratio between the smoking groups and never cigarette smokers seems to have been constant over the 18 years of follow up. Daily cigarette and pipe/cigar smokers had the greatest accumulated rate of stroke mortality.

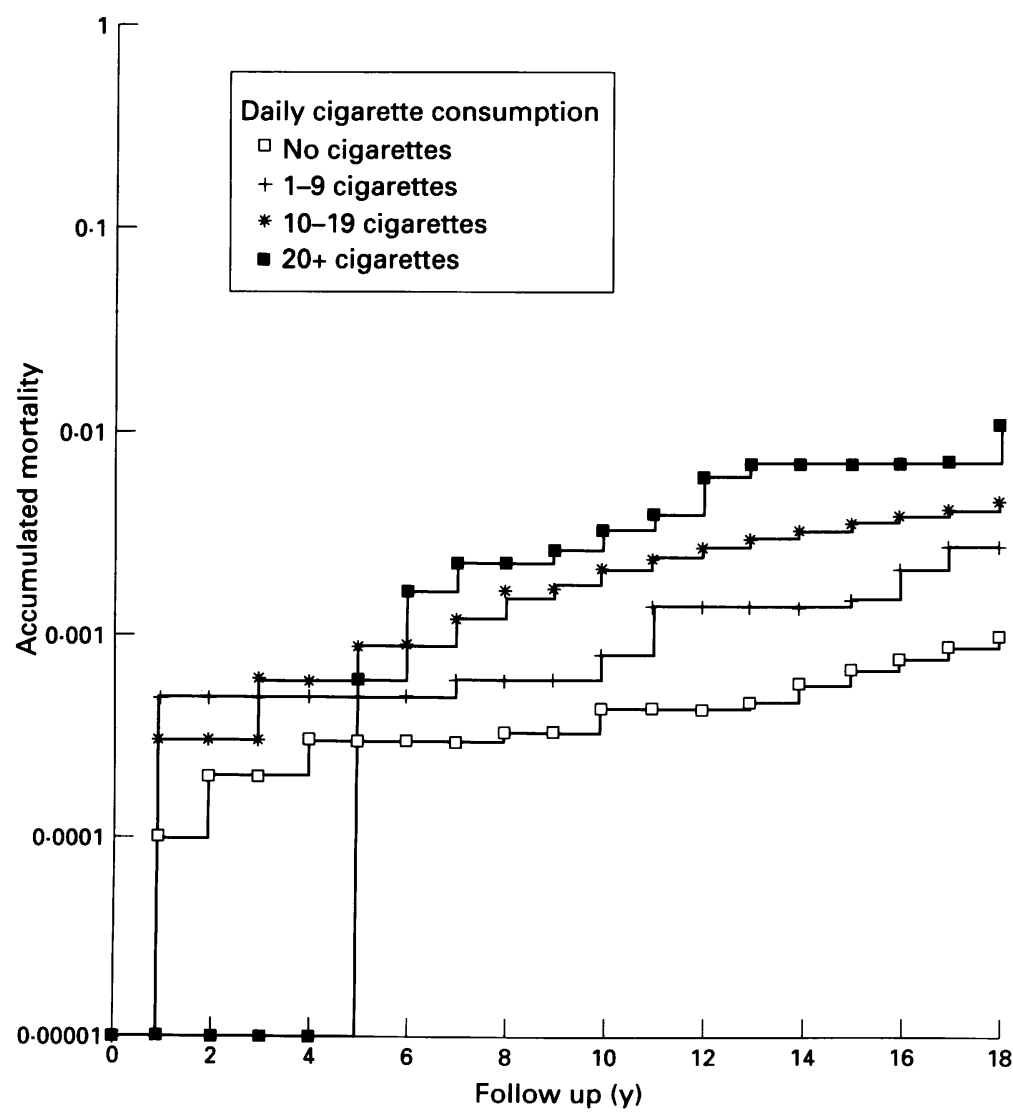

Figure 2 The accumulated risk of stroke mortality over 18 years (Aalen-Nelson) in relation to cigarette consumption in Oslo men.
Table 2 presents mean(SD) values of risk factors recorded for stroke cases compared with others for never and previous cigarette smokers versus daily smokers. Stroke cases had significantly higher levels of DBP and SBP than other men, but the absolute difference was twice as large for non-smokers compared with daily smokers. With regard to DBP, the differences were $12.1 \mathrm{mmHg}$ versus $6.5 \mathrm{mmHg}$ respectively, and for SBP the differences were $16.0 \mathrm{mmHg}$ versus $7.1 \mathrm{mmHg}$ respectively. BMI was a risk factor for stroke for never and previous cigarette smokers.

Analysis of risk in relation to daily cigarette consumption was done by the proportional hazards regression analysis (table 3 ). The analyses were carried out after adjustment for age only and for age, DBP, and glucose concentration, which had been found to be independent risk factors for stroke. ${ }^{13}$ The age adjusted relative risk ( $R R$ ) $(95 \%$ confidence interval (CI)) for daily smokers (cigarettes only or combined) compared with non-smokers was $3.5(2.2,5.7)$. The $R R$ was found to increase by $30 \%$ with an increase in consumption of five cigarettes. When analysing the $R R$ of cigarette consumption in terms of time since screening the rate ratio seemed to be constant over time between groups of cigarette smokers and nonsmokers (fig 2).

\section{Discussion}

The number of fatal stroke cases was low in this cohort of middle aged men. We have no data on changes in smoking habits during the follow up period in the group. In Norway, the proportion of men who were daily smokers fell from $51 \%$ in 1973 to $37 \%$ in $1993 .{ }^{14}$ ZeinerHenrichsen and Lund ${ }^{15}$ found that smoking related deaths in Norwegian men were highest for the age-group 35-44 years and fell with increasing age. The risk pattern seen is that of a young cohort in terms of stroke risk. The study of smoking and related habits in middle aged men with 18 years of follow up may indicate which risk factors will prove to be most predictive for stroke.

This analysis sheds light on the influence of different smoking habits on the risk of stroke. The increased risk seen with combined, daily cigarette and pipe or cigar smoking compared with daily smoking of pipe or cigars only is noteworthy; the crude and adjusted RR are over 2.5 times (log rank test; $p=0.03$ ). This confirms the findings of the British doctors' study $^{1}$ on the risk of smoking. However, our study showed that the combined group was at the highest risk, which is different from the British doctors' study. Hickey ${ }^{3}$ did not find this increased risk of mixed smoking among coronary heart disease patients but the number of cases in that study was small (1 case out of 37 at risk). They did confirm, however, that different smoking subgroups had different survival rates. Previous smokers had an increased but non-significant risk when compared with never smokers, as we found in this study.

Fatal cases of stroke were characterised by having increased DBP and SBP compared with 
non-cases. Twice the absolute differences were found among never and previous cigarette smokers compared with daily smokers. Never and previous cigarette smokers were also found to have increased BMI and glucose levels. Daily smokers were at risk of fatal stroke for blood pressures lower than that of never and previous smokers. These descriptive results indicate tolerance of higher blood pressure, increased BMI, and glucose among non-cigarette smokers, possibly due to the fact that their total burden of risk was less than in smokers.

Risk of fatal stroke in relation to the amount of cigarette smoking varies between studies. ${ }^{4}$ One meta-analysis ${ }^{10}$ showed a linearly increased risk of smoking with increasing amount. After 12 years' observation of the cardiovascularly healthy men in the Oslo Study ${ }^{16}$ we concluded that daily cigarette smoking was an independent risk factor, but no increased risk with increasing cigarette consumption could be found. It should be borne in mind that the numbers of fatal cases reported were low $(n=$ 26 ). In the present report, daily cigarette smoking remained a strong and independent risk factor after adjusting for age, DBP, and glucose in proportional hazards regression analysis.

In conclusion, information on smoking status remained strongly predictive after 18 years of follow up. Pipe or cigar smokers who also smoked cigarettes had an increased risk of fatal stroke. The increased risk of daily cigarette smoking was shown to increase with increasing cigarette consumption after 18 years.
1 Doll R, Peto R. Mortality in relation to smoking: 20 years' observations on male British doctors. BMF 1976;25:152535.

2 Doll R, Peto R, Wheatley K, Gray R, Sutherland I. Mortality in relation to smoking: 40 years' observations on male British doctors. BMJ 1994;309:901-11.

3 Hickey N, Mulcahy R, Daly L, Graham I, O'Donoghue S Kennedy C. Cigar and pipe smoking related to four year survival of coronary patients. Br Heart $\mathcal{f} 1983 ; 49: 423-6$.

4 Bonita R, Scragg R, Stewart A, Jackson R, Beaaglehole R Cigarette smoking and risk of premature stroke in men and women. BMF 1984;293:6-8.

5 Abbott RD, Yin Y, Reed DM, Yano K. Risk of stroke in male cigarette smokers. $N$ Engl f Med 1986;315:717-20.

6 Wolf PA, D'Agostino RB, Kannel WB, Bonita R, Belange AJ. Cigarette smoking as a risk factor for stroke. The Framingham Study. $\mathscr{f} A M A$ 1988;259:1025-9.

7 Donnan GA, McNeil JJ, Adena MA, Doyle AE, O'Malley HM, Neill GC. Smoking as a risk factor for cerebral ischaemia. Lancet 1989;ii:643-7.

8 Juvela S, Hillbom M, Numminen H, Koskinen P. Cigarette smoking and alcohol consumption as risk factors for aneurysmal subarachnoid hemorrhage. Stroke 1993;24: 639-46.

9 Robbins AS, Manson JE, Lee I, Satterfield S, Hennekens $\mathrm{CH}$. Cigarette smoking and stroke in a cohort of U.S. male physicians. Ann Intern Med 1994;120:458-62.

10 Shinton R, Beevers G. Meta-analysis of relation between cigarette smoking and stroke. $B M \mathcal{F} 1989 ; 298: 789-94$.

11 Higa $M$, Dvanipour $Z$. Smoking and stroke. Neuroepidemiology 1991;10:211-22.

12 Leren P, Askevold EN, Foss OP, Frøili A, Grymyr D, Helgeland A, Hjermann I, Holme I, Lund-Larsen PG, Norum KR. The Oslo study. Cardiovascular disease in middle-aged and young Oslo men. Acta Med Scand 1975; Suppl 588: 1-38.

13 Lund Håheim L, Holme I, Hjermann I, Leren P. Non-fasting serum glucose and the risk of fatal stroke in diabetics and non-diabetics. 18-years follow-up of the Oslo study. Stroke non-diabetics. 18-5.

14 Statens Tobakksskaderåd. Opp i røyk? Om tobakksbruk $i$ Norge gjennom 20 år: 1973-93. Oslo: Statens Tobakksskaderåd, 1994.

15 Zeiner-Henriksen T, Lund E. Mortality risk and smoking among middle aged Norwegian men. Tidsskr Nor Lœgeforen 1985;105:353-7.

16 Lund Håheim L, Holme I, Hjermann I, Leren P. Risk factors of stroke incidence and mortality. A 12 year followup of the Oslo study. Stroke 1993;24:1484-9. 